\title{
Cerambycidae (Coleoptera) da Colômbia.VII. Novos táxons, novos registros, nova sinonímia, nova combinação e novo nome
}

\author{
Ubirajara R. Martins ${ }^{1,3}$ \& Maria Helena M. Galileo ${ }^{2,3}$ \\ ${ }_{1}^{1}$ Museu de Zoologia, Universidade de São Paulo. Caixa Postal 42494, 04218-970 São Paulo, São Paulo, Brasil. \\ ${ }^{2}$ Museu de Ciências Naturais, Fundação Zoobotânica do Rio Grande do Sul. Caixa Postal 1188, 90001 -970 Porto Alegre, \\ Rio Grande do Sul, Brasil. \\ 3 Pesquisador do CNPq.
}

ABSTRACT. Cerambycidae (Coleoptera) da Colômbia. VII. Novos táxons, novos registros, nova sinonímia, nova combinação e novo nome. New taxa described from Colombia, Amazonas: Xenofrea triangularis sp. nov. (Xenofreini); Boyaca: Neoclytus canescens sp. nov. (Clytini); Epropetes variabile sp. nov. (Tillomorphini); Oreodera advena sp. nov.; Irundisaua gen. nov, type species I. ocularis sp. nov. (Acanthoderini); Cauca: Ischiocentra punctata sp. nov. (Onciderini); Caquetá: Oreodera adornata sp. nov. (Acanthoderini); Chocó: Oreodera nivea sp. nov. (Acanthoderini); Magdalena: Mecometopus arixi sp. nov. (Clytini); Nariño: Carterica rubra sp. nov. (Colobotheini); Putumayo: Eburodacrys guttata sp. nov. (Eburiini); Valle del Cauca: Blabia bicolor sp. nov. (Desmiphorini). New records from Colombia, Amazonas: Criodion cinereum (Olivier, 1795); Coleoxestia atrata (Gounelle, 1909); Eburodacrys quadridens (Fabricius, 1801); E. rufispinis Bates, 1870; E. sulphureosignata (Erichson, 1847); Rhomboidederes minutus Napp \& Martins, 1984; Aneuthetochorus conjunctus Napp \& Martins, 1984; Lissozodes basalis White, 1855; Mecometopus latecinctus Bates, 1870; Chrysoprasis aureicollis White, 1853; Oreodera curvata Martins \& Monné, 1993; Carterica cincticornis Bates, 1865; Magdalena: Atenizus castaneus Martins, 1981; Vichada: Eusapia guyanensis Huedepohl, 1988; Gnomidolon biarcuatum (White, 1855); Tropidion subcruciatum (White, 1855); Sthelenus ichneumoneus Buquet, 1859; Putumayo: Hemilissa opaca Martins, 1976; H. sulcicollis Bates, 1870; Glyptoscapus flaveolus (Bates, 1870); Orthostoma abdominale (Gyllenhal, 1817); Oreodera melzeri Monné \& Fragoso, 1988; Caquetá: Gnomidolon conjugatum (White, 1855); Cauca: Mecometopus macilentus Bates, 1872; Tolima: Cherentes niveilateris (Thomson, 1868). New synonym established: Necalphus maranduba Galileo \& Martins, 2003 = Myoxomorpha decorata Monné \& Magno, 1992 and the new combination proposed: Necalphus decoratus (Monné \& Magno, 1992) comb. nov. Cotyadesmus new name proposed for Paradesmus Galileo \& Martins, 2003 preoccupied in Myriapoda.

KEY WORDS. Geographical distribution, taxonomy.

RESUMO. Novos táxons descritos da Colômbia, Amazonas: Xenofrea triangularis sp. nov. (Xenofreini); Boyaca: Neoclytus canescens sp. nov. (Clytini); Epropetes variabile sp. nov. (Tillomorphini); Oreodera advena sp. nov.; Irundisa gen. nov, type species I. ocularis sp. nov. (Acanthoderini); Cauca: Ischiocentra punctata sp. nov. (Onciderini); Caquetá: Oreodera adornata sp. nov. (Acanthoderini); Chocó: Oreodera nivea sp. nov. (Acanthoderini); Magdalena: Mecometopus arixi sp. nov. (Clytini); Nariño: Carterica rubra sp. nov. (Colobotheini); Putumayo: Eburodacrys guttata sp. nov. (Eburiini); Valle del Cauca: Blabia bicolor sp. nov. (Desmiphorini). Novos registros: Colômbia, Amazonas: Criodion cinereum (Olivier, 1795); Coleoxestia atrata (Gounelle, 1909); Eburodacrys quadridens (Fabricius, 1801); E. rufispinis Bates, 1870; E. sulphureosignata (Erichson, 1847); Rhomboidederes minutus Napp \& Martins, 1984; Aneuthetochorus conjunctus Napp \& Martins, 1984; Lissozodes basalis White, 1855; Mecometopus latecinctus Bates, 1870; Chrysoprasis aureicollis White, 1853; Oreodera curvata Martins \& Monné, 1993; Carterica cincticornis Bates, 1865; Magdalena: Atenizus castaneus Martins, 1981; Vichada: Eusapia guyanensis Huedepohl, 1988; Gnomidolon biarcuatum (White, 1855); Tropidion subcruciatum (White, 1855); Sthelenus ichneumoneus Buquet, 1859; Putumayo: Hemilissa opaca Martins, 1976; H. sulcicollis Bates, 1870; Glyptoscapus flaveolus (Bates, 1870); Orthostoma abdominale (Gyllenhal, 1817); Oreodera melzeri Monné \& Fragoso, 1988; Caquetá: Gnomidolon conjugatum (White, 1855); Cauca: Mecometopus macilentus Bates, 1872; Tolima: Cherentes niveilateris (Thomson, 1868). Nova sininímia: Necalphus maranduba Galileo \&Martins, 2003 = Myoxomorpha decorata Monné \& Magno, 1992 e proposta a nova combinação: Necalphus decoratus (Monné \& Magno, 1992) comb. nov. Cotyadesmus, novo nome, é dado para Paradesmus Galileo \& Martins, 2003 pré-ocupado em Myriapoda.

PALAVRAS CHAVE. Distribuição geográfica, taxonomia. 
Esta é a sétima contribuição sobre os Cerambycidae da Colômbia. Os trabalhos que precederam sobre o mesmo tema foram publicados por Martins \& Galileo (2002a, b, 2003) e por Galileo \& Martins (2003a, b, c). Além de um gênero novo e 12 espécies novas, apresentam-se novas ocorrências para 26 espécies, propõe-se uma sinonímia a nível específico e estabelece-se um novo nome para nome genérico pré-ocupado.

O material pertence, quase na sua totalidade, ao Instituto Alexander von Humboldt, Villa de Leyva (IAHC), foi enviado pelo Dr. Fernando Fernández e pela Biól. Claudia Martínez. As coletas ocorreram especialmente em Parques Nacionais: PNN Amacaiacu (Amazonas), SFF Iguaque (Boyaca), PNN Isla Gorgona (Cauca), PNN Enseada de Utría (Chocó), PNN Tayrona (Magdalena), RN La Planada (Nariño), PNN La Paya (Putumayo) e PNN Tuparro (Vichada).

As referências bibliográficas sob cada táxon estão restritas à descrição original, ao catálogo de Monné (1993a-i, 1994ac, 1995) e as posteriores a esse catálogo.

As siglas das instituições arroladas no texto correspondem ao Museu de Ciências Naturais, Porto Alegre (MCNZ); Museu Nacional de História Natural, Santafe de Bogotá e (MNHB) e Museu de Zoologia, Universidade de São Paulo (MZSP). As dimensões são fornecidas em milímetros.

\section{Cerambycinae Oemini}

\section{Atenizus castaneus Martins, 1981}

Atenizus castaneus Martins, 1981: 10; 1997: 26; Monné, 1993a: 22 (cat.).

Originalmente descrita da Venezuela, Aragua, até agora só era conhecida desse país. Registra-se agora para a Colômbia.

Material examinado. Colômbia, Magdalena: Parque Nacional Natural Tayrona (Pueblito, $11^{\circ} 20^{\prime} \mathrm{N}, 74^{\circ} 2^{\prime} \mathrm{W}, 225 \mathrm{~m}$ ), macho, 29.VI.-14.VII.2000, R. Henriquez leg., armadilha de Malaise (IAHC).

\section{Cerambycini Criodion cinereum (Olivier, 1795)}

Prionus cinereus Olivier, 1795: (66) 35, est. 13, fig. 55.

Criodion cinereum; Gahan, 1892: 24; Monné, 1993c: 8 (cat.); Martins \& Monné, no prelo: 201.

Descrita do Suriname, foi registrada para Guiana Francesa, Peru, Brasil (Amazonas) e Bolívia (Martins \& Monné, no prelo).

Material examinado. Colômbia, Amazonas: Parque Nacional Natural Amacayacu (Mocacagua, $3^{\circ} 41^{\prime} \mathrm{S}, 70^{\circ} 15^{\prime} \mathrm{W}$ ), fêmea, 31.VII -7.VIII.2000, A. Parente leg., armadilha de Malaise (IAHC).

\section{Coleoxestia atrata (Gounelle, 1909)}

Xestia atrata Gounelle, 1909: 612.

Coleoxestia atrata; Aurivillius, 1912: 64 (cat.); Monné, 1993c: 14 (cat.); Martins \& Monné, no prelo: 165.

Coleoxestia nigra Lane, 1956: 12; Martins \& Monné, no prelo: 165 (sin.).

Revista Brasileira de Zoologia 22 (1): 5-18, março 2005
Coleoxestia atrata foi originalmente descrita de Goiás e o sinônimo do Paraná e de Goiás. Foi registrada por Martins \& Monné (no prelo) para Tocantins.

Material examinado. Colômbia, Amazonas: Parque Nacional Natural Amacayacu (Mocagua, $3^{\circ} 41^{\prime} \mathrm{S}, 70^{\circ} 15^{\prime} \mathrm{W}, 150 \mathrm{~m}$ ), fêmea, 3-9.IV.2000, A. Parente leg., armadilha de Malaise (IAHC).

\section{Eburiini}

\section{Eburodacrys sulphureosignata (Erichson, 1847)}

Eburia sulphureo-signata Erichson, 1847: 140.

Coeleburia sulphureo-signata; Kirsch, 1875: 285.

Eburodacrys sulphureosignata; Bodkin, 1919: 267 (distr.); Martins, 1997: 65; 1999: 366; Monné, 1993b: 44 (cat.); 2001: 56 (cat.);

Tavakilian et al., 1997: 336 (hosp).

Eburodacrys longipilis Bates, 1870: 268.

Originalmente descrita do Peru, foi assinalada por MarTins (1999) para Trinidad, Guiana, Suriname, Guiana Francesa, Peru, Brasil (Amazonas, Acre, Rondônia, Mato Grosso, Goiás), Bolívia.

Material examinado. Colômbia, Amazonas: Parque Nacional Natural Amacayacu (Mocagua, $3^{\circ} 41^{\prime} \mathrm{S}, 70^{\circ} 15^{\prime} \mathrm{W}, 150 \mathrm{~m}$ ), fêmea, 11-24.IV.2000, A. Parente leg., armadilha de Malaise (IAHC).

\section{Eburodacrys rufispinis Bates, 1870}

Eburodacrys rufispinis Bates, 1870: 269; Monné, 1993b: 43 (cat.); Martins, 1997: 64; 1999: 355.

Eburodacrys rufispinis já teve ocorrências registradas para Guiana Francesa, Brasil (Amazonas, Pará), Peru e Bolívia.

Material examinado. Colômbia, Amazonas: Parque Nacional Natural Amacayacu (Mocagua, $3^{\circ} 41^{\prime} \mathrm{S}, 70^{\circ} 15^{\prime} \mathrm{W}, 150 \mathrm{~m}$ ), fêmea, 4-28-VIII.2000, A. Parente leg., armadilha de Malaise (IAHC).

\section{Eburodacrys quadridens (Fabricius, 1801)}

Stenocorus 4-dens Fabricius, 1801: 308.

Eburodacrys quadridens; Aurivillius, 1912: 82 (cat.); Monné, 1993b: 42 (cat.); Martins, 1997: 64; 1999: 358.

Eburia virgo Newman, 1840: 196.

Eburodacrys virgo; Thomson, 1864: 241.

Eburodacrys citreoguttata Thomson, 1860: 240.

A distribuição geográfica conhecida envolvia Guiana Francesa, Brasil (Roraima, Amazonas, Acre, Pará, Pernambuco), Peru e Bolívia; ora é registrada para a Colômbia.

Material examinado. Colômbia, Amazonas: Parque Nacional Natural Amacayacu (Mocagua, $3^{\circ} 41^{\prime} \mathrm{S}, 70^{\circ} 15^{\prime} \mathrm{W}, 150 \mathrm{~m}$ ), fêmea, 3-9.IV.2000, A. Parente leg., armadilha de Malaise (IAHC).

\section{Eburodacrys guttata sp. nov.}

Fig. 1

Etimologia. Latim, guttatus = manchado.

Colorido geral laranja-avermelhado. Tubérculos pronotais pretos, esta coloração continuada, posteriormente, até o meio do pronoto. Espinhos laterais do protórax, mancha entre esses 

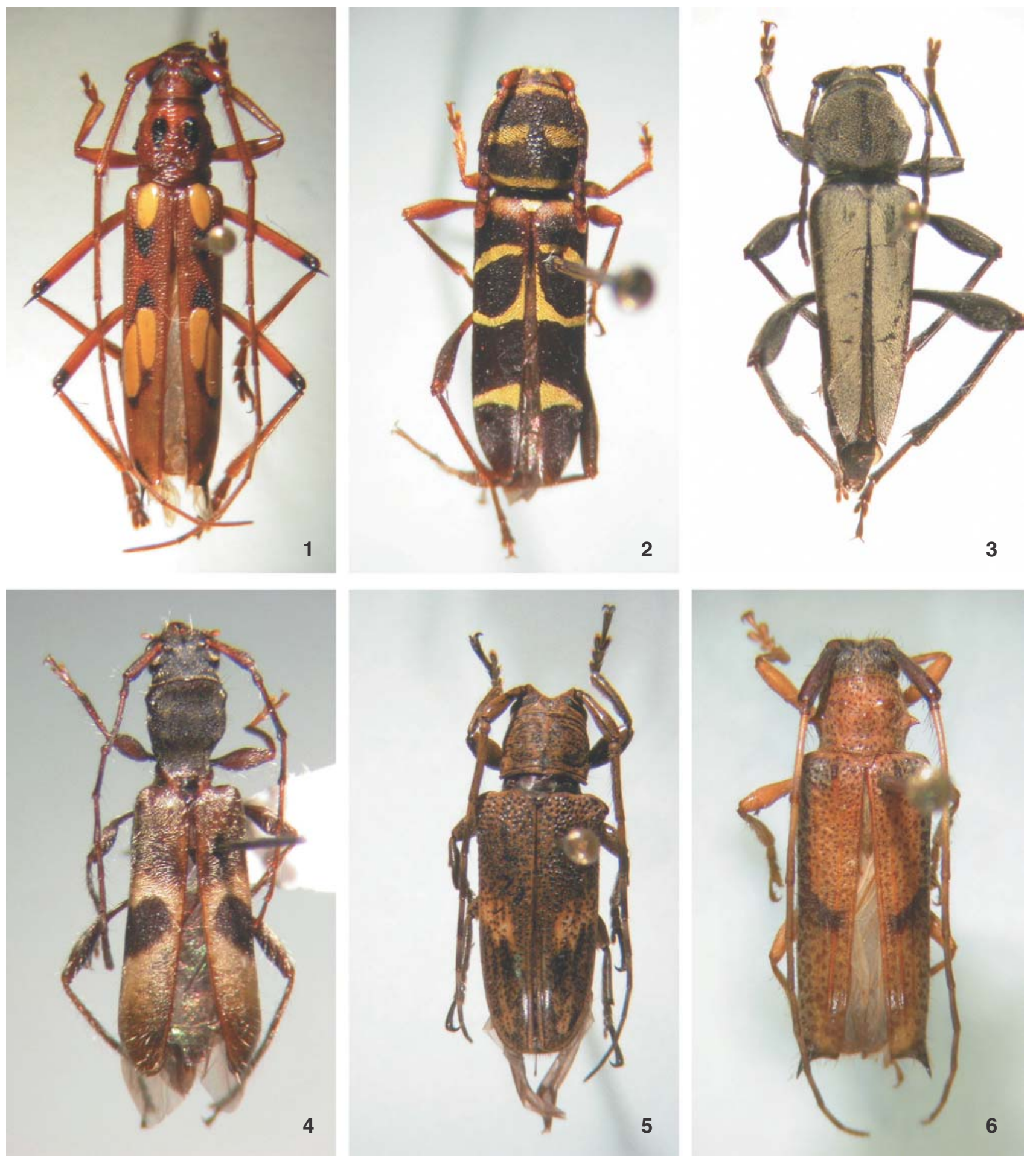

Figuras 1-6. Habitus. (1) Eburodacrys guttata sp. nov., holótipo fêmea,16,9 mm; (2) Mecometopus arixi sp. nov., parátipo fêmea,10,6 mm; (3) Neoclytus canescens sp. nov., holótipo macho, 16,3 mm; (4) Epropetes variabile sp. nov., parátipo macho, 7,1 mm; (5) Ischiocentra punctata sp. nov., holótipo fêmea, 14,1 mm; (6) Blabia bicolor sp. nov., holótipo fêmea, 13,4mm. 
espinhos e margem anterior, pretos. Cada élitro com três manchas ebúrneas: uma basal, elíptica, apenas mais curta do que a central-interna; duas atrás do meio separadas por faixa estreita, a central-interna inicia-se adiante da central-externa que é adelgaçada para a parte posterior. Região posterior da mancha basal; regiões anterior e posterior das manchas centrais, pequena mancha triangular contígua aos espinhos e espinhos apicais dos élitros, pretos. Pequena extensão do ápice dos meso- e metafêmures e espinhos, pretos. Escapo esbelto, gradualmente engrossado para o ápice. Pronoto com rugas irregulares; tubérculos ântero-laterais desenvolvidos, arredondados no topo e longitudinais; gibosidade central pouco elevada. Tubérculo ânterolateral do protórax não demarcado; espinho central curto. Mesosterno sem tubérculo. Espículo da epipleura evidente. Espinhos elitrais e femorais, longos.

Dimensões. Comprimento total, 16,9-17,9; comprimento do protórax, 3,3-3,5; maior largura do protórax, 3,3-3,4; comprimento do élitro, 12,8-13,0; largura umeral, 3,9-4,0.

Material-tipo. Holótipo fêmea, Colômbia, Putumayo: Parque Nacional Natural La Paya, (Cabaña Chagra, $0^{\circ} 7^{\prime} \mathrm{S}, 74^{\circ} 56^{\prime} \mathrm{W}$, 320m), 15-30.X.2001, L. Cobete leg., armadilha de Malaise (IAHC). Parátipo fêmea, mesmos dados do holótipo (MZSP).

Discussão. Pela chave publicada por Martins (1999), Eburodacrys guttata é discriminada no item 65 por sua semelhança com E. prolixa Monné \& Martins, 1992 e E. sexguttata Lameere, 1884. Distingue-se de E. prolixa, pela ausência de mancha preta no vértice; pelo centro do pronoto com rugas; pela ausência de mancha preta justaposta ao tubérculo pronotal e prolongada posteriormente; pela mancha ebúrnea central-externa disposta logo atrás da central-interna. Em E. prolixa, o vértice tem mancha preta; o centro do pronoto tem rugas e pontos; a coloração preta está restrita aos tubérculos pronotais e a mancha ebúrnea central externa inicia-se no nível do meio da central interna.

Separa-se de E. sexguttata pela ausência de mancha preta no vértice; pelo pronoto e partes laterais do protórax sem faixas pretas e pelos élitros sem costas atrás das manchas ebúrneas centrais. Em E. sexguttata geralmente o vértice tem mancha preta; o pronoto tem faixas pretas; as partes laterais do protórax têm faixa preta contínua do tubérculo até quase a margem anterior e as manchas ebúrneas centrais são continuadas por costas contrastantes. Além disso, E. sexguttata ocorre na Mata Atlântica, da Paraíba ao Rio Grande do Sul, no Paraguai e na Argentina (Misiones).

\section{Hesperophanini}

\section{Eusapia guyanensis Huedepohl, 1988}

Eusapia guyanensis Huedepohl, 1988: 526; Monné, 1993b: 15 (cat.); Tavakilian et al., 1997: 345 (hosp.); Martins \& Galileo, 1999: 32.

Descrita da Guiana Francesa, E. guyanensis foi assinalada para o Brasil (Amazonas e Pará) por MARTins \& GALILEO (1999).

Material examinado. ColômBia, Vichada: Parque Nacional Natural Tuparro, (Bosque Sabana, $5^{\circ} 21^{\prime} \mathrm{N}, 67^{\circ} 51^{\prime} \mathrm{W}, 100 \mathrm{~m}$ ), fêmea, 15-29.VI.2000, W. Villalba leg., armadilha de Malaise (IAHC).

\section{Elaphidionini \\ Rhomboidederes minutus Napp \& Martins, 1984}

Rhomboidederes minutus Napp \& Martins, 1984b: 132, fig. 6; Monné, 1993d: 84 (cat.).

Estava assinalada até agora para Suriname, Guiana Francesa, Brasil (Pará) e Bolívia.

Material examinado. ColômBia, Amazonas: Parque Nacional Natural Amacayacu (San Martín, 3²3’S, 7006’W, 150 m), fêmea, 12-19.VI.2000, B. Amado leg., armadilha de Malaise (IAHC).

\section{Piezocerini \\ Hemilissa opaca Martins, 1976}

Hemilissa opaca Martins, 1976: 289; 2003: 148; Monné, 1993c: 31 (cat.); Tavakilian et al., 1997: 329, 342, 343 (hosp.).

Descrita originalmente da Guiana (Rio Essequibo, Rockstone) foi assinalada por MARTINs (2003) para Venezuela, Guiana Francesa e Brasil (Amazonas, Roraima, Pará).

Material examinado. Colômbia, Putumayo: Parque Nacional Natural La Paya, (Cabaña La Paya, $0^{\circ} 2^{\prime} \mathrm{S}, 75^{\circ} 12^{\prime} \mathrm{W}, 330 \mathrm{~m}$ ), macho, 20.XI-5.XII.2001, E. Lozano leg., armadilha de Malaise (IAHC).

\section{Hemilissa sulcicollis Bates, 1870}

Hemilissa sulcicollis Bates, 1870: 284; Monné, 1993c: 30 (cat.); Martins, 2003: 150, figs 168, 175.

Esta espécie tem distribuição muito vasta na América do Sul e já foi registrada para o Peru, a Guiana Francesa, o Brasil (Amazonas, Pará, Rondônia, Mato Grosso, Mato Grosso do Sul, Goiás, Rio Grande do Norte, Pernambuco, Minas Gerais, Espírito Santo, Rio de Janeiro, São Paulo) e a Bolívia (MArtins, 2003).

Material examinado. Colômbia, Putumayo: Parque Nacional

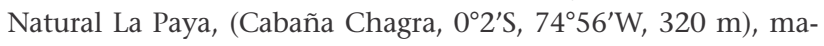
cho, 15-30.X.2001, L. Cobete leg., armadilha de Malaise (IAHC).

\section{Ibidionini \\ Glyptoscapus flaveolus (Bates, 1870)}

Hexoplon flaveolus Bates, 1870: 285

Gnomidolon flaveolum; Gemminger \& Harold, 1872: 2827 (cat.) Glyptoscapus flaveolus; Martins, 1967: 84; Monné, 1993e: 6 (cat.).

Descrita de Tefé, Amazonas, Brasil, Glyptoscapus flaveolus foi dada como ocorrente no Pará (Martins 1967). Amplia-se para a Colômbia.

Material examinado. Colômbia, Putumayo: Parque Nacional Natural La Paya (Nascimiento, Quebrada Blanca, $0^{\circ} 1$ 's, $75^{\circ} 12^{\prime} \mathrm{W}, 330 \mathrm{~m}$ ), fêmea, 25.XI.2001, D. Campos leg., captura manual, (IAHC).

\section{Gnomidolon biarcuatum (White, 1855)}

Ibidion biarcuatum White, 1855: 228

Gnomidolon biarcuatum; Thomson, 1864: 219; Monné, 1993e: 10 (cat.).

Gnomidolon excelsum Martins, 1962: 274.

Revista Brasileira de Zoologia 22 (1): 5-18, março 2005 
Esta espécie foi registrada por MARTins (1967) para a Guiana, Guiana Francesa, Peru, Brasil (Amazonas, Pará e Mato Grosso). Assinala-se agora para a Colômbia.

Material examinado. Colômbia, Vichada: Parque Nacional Natural Tuparro, (Bosque Sabana, $5^{\circ} 21^{\prime} \mathrm{N}, 67^{\circ} 51^{\prime} \mathrm{W}, 100 \mathrm{~m}$ ), fêmea 8-18.VIII.2000, W. Villalba leg., armadilha de Malaise (IAHC).

\section{Gnomidolon conjugatum (White, 1855)}

Ibidion conjugatum White, 1855: 231.

Octoplon ? conjugatum; Thomson, 1867: 158.

Gnomidolon? conjugatum; Lacordaire, 1869: 330.

Gnomidolon conjugatum; Bates, 1870: 287; Monné, 1993e: 11 (cat.). Gnomidolon eganum Bates, 1870: 287.

Martins (1967) registrou G. conjugatum para o Peru, o Brasil (Amazonas, Pará) e a Bolívia. Assinala-se agora para a Colômbia.

Material examinado. Colômbia, Caquetá: San José de Fragua, $\left(1^{\circ} 20^{\prime} \mathrm{N}, 76^{\circ} 6^{\prime} \mathrm{W}, 100 \mathrm{~m}\right)$, macho, 3-8.IX.2000, E. González leg., armadilha de Malaise (IAHC).

\section{Tropidon subcruciatum (White, 1855)}

Ibidion subcruciatum White, 1855: 226;

Tropidion subcruciatum; Martins, 1968: 427, est. 14, fig. 2;

Monné, 1993e: 29 (cat.).

Ibidion spinipenne Thomson, 1865: 570.

Ibidion subcruciatum var. spinipenne Gounelle, 1909: 677.

Octoplon calligrammum Bates, 1870: 294.

Tropidon subcruciatum tem distribuição ampla e foi registrada por MARTins (1968) para o Suriname, o Brasil (Roraima, Amazonas, Pará, Mato Grosso do Sul, Goiás e da Paraíba ao Paraná). Acrescenta-se agora o registro mais setentrional.

Material examinado. ColômBIA, Vichada: Parque Nacional

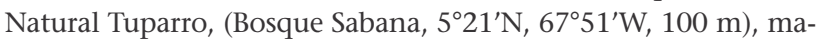
cho, 15-29.VI.2000, W. Villalba leg., armadilha de Malaise (IAHC).

\section{Callidiopini}

\section{Aneuthetochorus conjunctus Napp \& Martins, 1984}

Aneuthetochorus conjunctus Napp \& Martins, 1984a: 53; Monné, 1993f: 6 (cat.).

Originalmente descrita do Brasil, Amazonas: Manaus (Reserva Ducke, AM 010, km 26). Assinala-se agora para a Colômbia.

Material examinado. Colômbia, Amazonas: Parque Nacional Natural Amacayacu (Matamata, $3^{\circ} 23^{\prime} \mathrm{S}, 70^{\circ} 06^{\prime} \mathrm{W}, 150 \mathrm{~m}$ ), fêmea, 12-19.III.2000, A. Parente leg., armadilha de Malaise (IAHC).

\section{Necyladopsini}

\section{Lissozodes basalis (White, 1855)}

Cycnoderus basalis White, 1855: 213, est. 7, fig. 5.

Cycnoderus ? basalis; Lacordaire, 1869: 112.

Lissozodes basalis; Bates, 1870: 409; Monné, 1994a: 19 (cat.).
Conhecida apenas da localidade-tipo, Tefé, Amazonas, Brasil, ora registrada para a Colômbia.

Material examinado. Colômbia, Amazonas: Parque Nacional Natural Amacayacu (Matamata, $3^{\circ} 23^{\prime} \mathrm{S}, 70^{\circ} 06^{\prime} \mathrm{W}, 150 \mathrm{~m}$ ), macho, 27.III-3.IV.2000, A. Parente leg., armadilha de Malaise (IAHC).

\section{Sthelenus ichneumoneus Buquet, 1859}

Sthelenus ichneumoneus Buquet, 1859: 622, est. 14, fig. 4; Tavakilian in Hequet, 1996: est. 8, fig. 1; Monné, 1993g: 9 (cat.).

Sthelenus ischneumoneus; Thomson, 1864: 212; 1878: 17 (error). Sthelenus braconinus Bates, 1870: 315.

Monné (1993g) assinalou Sthelenus ichneumoneus para a Guiana Francesa e para o Brasil (Amazonas). Amplia-se para a Colômbia.

Material examinado. Colômbia, Vichada: Parque Nacional Natural Tuparro, (Centro Administrativo, $5^{\circ} 21^{\prime} \mathrm{N}, 67^{\circ} 51^{\prime} \mathrm{W}$, 100 m), macho, 22.V-3.VI.2001, I. Gill leg., armadilha de Malaise (IAHC).

\section{Compsocerini \\ Orthostoma abdominale (Gyllenhal, 1817)}

Cerambyx abdominalis Gyllenhal in Schoenherr, 1817: 157. Callichroma abdominalis; Dejean, 1821: 105 (cat.).

Orthostoma abdominalis; Lacordaire, 1830: 174; Monné, 1993h:

21 (cat.); Napp, 1994: 653, figs 1-35.

Orthoschema abdominalis; Thomson, 1864: 261.

Orthoschema (Orthoprasis) abdominalis; Aurivillius, 1910: 159. Orthoprasis abdominalis; Aurivillius, 1926: 3 (distr.).

NAPP (1994), ao rever o gênero Orthostoma, apresentou mapa com as ocorrências de $O$. abdominale da qual reconheceu duas formas, uma com protórax verde-metálico, outra com protórax verde-dourado a dourado. O exemplar colombiano enquadra-se no primeiro padrão e amplia a distribuição desta forma que já foi registrada para Equador, Peru, Brasil (Amazonas, Rondônia, Mato Grosso do Sul, Goiás, da Bahia a Santa Catarina), Paraguai e Argentina. A forma com protórax verdedourado foi assinalada para Equador, Brasil (Amazonas, Pará, Rondônia, Mato Grosso).

Material examinado. ColômBIA, Putumayo: Parque Nacional Natural La Paya, (Cabaña La Paya, $0^{\circ} 2^{\prime} \mathrm{S}, 75^{\circ} 12^{\prime} \mathrm{W}, 330 \mathrm{~m}$ ), macho, 20.XI-5.XII.2001, E. Lozano leg., armadilha de Malaise (IAHC).

\section{Clytini \\ Mecometopus Iatecinctus Bates, 1870}

Mecometopus latecinctus Bates, 1870: 398; Monné, 1993i: 29 (cat.).

Clytus latecinctus; Gemminger \& Harold, 1872: 2931 (cat.).

Descrita originalmente do Brasil, Amazonas: São Paulo de Olivença e registrada para a Venezuela, Amazonas: Surinomi. Expande-se a distribuição para a Colômbia.

Revista Brasileira de Zoologia 22 (1): 5-18, março 2005 
Material examinado. Colômbia, Amazonas: Parque Naci-

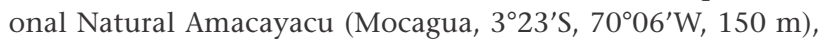
fêmea, 14-21.VIII.2000, A. Parente leg., armadilha de Malaise (IAHC); Putumayo: Parque Nacional Natural La Paya, (Cabaña Chagra, $0^{\circ} 7^{\prime} \mathrm{S} 74^{\circ} 56^{\prime} \mathrm{W}, 320 \mathrm{~m}$ ), macho, 1-15.V.2001, E. Lozano leg., armadilha de Malaise (IAHC).

\section{Mecometopus macilentus Bates, 1872}

Mecometopus macilentus Bates, 1872: 187; Monné, 1993i: 30 (cat.); Maes et al., 1994: 16 (distr.).

Mecometopus macilentus só era conhecida da América Central (Nicarágua ao Panamá) e registra-se agora para a América do Sul.

Material examinado. Colômbia, Cauca: Parque Nacional Natural Isla Gorgona (El Saman, $2^{\circ} 58^{\prime} \mathrm{N}, 78^{\circ} 11^{\prime} \mathrm{W}, 5 \mathrm{~m}$ ), macho, 12-28.IX.2001, H. Torres leg., armadilha de Malaise (IAHC).

\section{Mecometopus arixi sp. nov.}

Fig. 2

Etimologia. Tupi, arixi $=$ faceiro.

Tegumento preto na cabeça, protórax, antenômeros III e IV (base do V), élitros, exceto extremo basal, dois terços apicais dos metafêmures e face ventral do corpo. Tegumento vermelhoalaranjado: escapo, pedicelo, antenômeros apicais, base dos élitros, pernas anteriores e médias, metatíbias e metatarsos. Pubescência amarela, densa, reveste a fronte menos faixa estreita central, faixa transversal estreita ao redor da parte posterior da cabeça, faixas transversais no pronoto: junto à orla anterior, junto à orla basal e no meio onde é interrompida no centro pela fileira de grânulos, prosterno, escutelo, três faixas em cada élitro (uma no quinto anterior, levemente ascendente da margem para a sutura, uma no meio, transversal que emite um prolongamento sutural até quase a primeira faixa, uma transversal no terço apical, apenas mais larga no lado da sutura), mesepimeros, extremo lateral do mesosterno, regiões anterior e posterior do metasterno, metade posterior dos metepisternos, faixas largas na metade posterior dos urosternitos I a IV. Fileira de grânulos pronotais contínua entre as duas faixas de pubescência amarela.

Dimensões. Comprimento total, 8,9-10,6; comprimento do protórax, 2,2-2,8; maior largura do protórax, 2,2-2,8; comprimento do élitro, 6,1-7,3; largura umeral, 2,4-3,0.

Material-tipo. Holótipo fêmea, ColômBia, Magdalena, Parque Nacional Natural Sierra Nevada de Santa Marta (El Ramo, $\left.10^{\circ} 48^{\prime} \mathrm{N}, 73^{\circ} 39^{\prime} \mathrm{W}, 2500 \mathrm{~m}\right), 27 . I I-14 . I I I .2001$, J. Cantillo leg., armadilha de Malaise (IAHC). Parátipos: mesma procedência, fêmea, 29.XII.2000-15.I.2001, J. Cantillo leg., armadilha de Malaise (MCNZ); fêmea, 15-29.I.2001, J. Cantillo leg., armadilha de Malaise (IAHC); fêmea, 29.I-15.II.2001, J. Cantillo leg., armadilha de Malaise (MZSP).

Discussão. Mecometopus arixi sp. nov. assemelha-se, pela descrição, a M. melanion Bates, 1885. Difere pelo tegumento alaranjado de diversas partes corporais; pelo escutelo recoberto por pubescência amarelada e pela ausência da mancha apical nos élitros. Em M. melanion o tegumento é todo preto; o escutelo é revestido por pubescência cinérea e o ápice dos élitros tem pequena mancha cinérea.

\section{Neoclytus canescens sp. nov.}

Fig. 3

Etimologia. Latim, canescens $=$ acinzentado.

Tegumento preto, mais avermelhado nos tarsos. Fronte com duas faixas laterais, estreitas, de pubescência branco-amarelada; faixa de pubescência esbranquiçada atrás dos olhos. Gula com longos pêlos esbranquiçados. Antenas com 11 artículos, atingem o terço basal dos élitros; pubescência avermelhada nos antenômeros apicais. Protórax com nítida gibosidade lateral. Pronoto com pubescência branca entremeada pela pontuação densa e fina; área centro-longitudinal tuberculada e em duas pequenas elevações glabras, laterais, no nível do centro. Prosterno, mesosterno, centro do metasterno e dos urosternitos com pêlos finos e esbranquiçados. Pubescência branca, densa, na parte posterior dos metepisternos e metepimero; mais esparsa nos lados dos urosternitos I e II. Escutelo com pilosidade esbranquiçada nas bordas. Élitros com o dorso inteiramente coberto por pubescência esbranquiçada exceto faixa lateral sobre a declividade praticamente glabra; extremidades elitrais obliquamente truncadas com espinho no lado externo. Profêmures com grânulos $(20$ x) no lado externo da face ventral. Mesofêmures com pêlos finos e brancos na face ventral; extremidades com as abas apicais aguçadas. Metafêmures com pêlos brancos e longos na face ventral e na metade basal da face dorsal; extremidades com as abas apicais aguçadas. Metatíbias com pêlos brancos entremeados por pêlos mais avermelhados em toda a face interna.

Dimensões. Comprimento total, 16,3; comprimento do protórax, 4,0; maior largura do protórax, 4,7; comprimento do élitro, 11,4; largura umeral, 4,9.

Material-tipo. Holótipo macho, ColômBIA, Boyaca: SFF Iguaque (Cabaña Mamarramos, $\left.5^{\circ} 25^{\prime} \mathrm{N}, 73^{\circ} 27^{\prime} \mathrm{W}, 2855 \mathrm{~m}\right), 4$ 21.XII.2000, P. Reina leg., armadilha de Malaise (IAHC).

Discussão. Protórax com gibosidade lateral é carater raro entre as espécies de Neoclytus Thomson, 1860, mas pode ser encontrado em N. armaticollis Zajciw, 1964 e N. moritzii Thomson, 1860. Neoclytys canescens sp. nov. distingue-se de ambas pela pubescência esbranquiçada e uniforme do dorso dos élitros. Tanto em N. armaticollis como em N. moritzii os élitros apresentam faixas estreitas de pubescência esbranquiçada ou amarelada.

\section{Tillomorphini Epropetes variabile sp. nov.} Fig. 4

Etimologia. Latim, variabilis $=$ variável.

Cabeça preta com pubescência branco-amarelada esparsa; vértice com pontuação rasa e microesculturada; tubérculos anteníferos elevados. Olhos divididos. Antenas avermelhadas; escapo, pedicelo, antenômeros III e IV com as extremidades mais

Revista Brasileira de Zoologia 22 (1): 5-18, março 2005 
escurecidas. Pronoto microesculturado com pontos rasos, exceto em duas áreas arredondadas, uma de cada lado, à frente do estreitamento basal; pilosidade amarelada no estrangulamento basal e em duas áreas pequenas látero-anteriores. Élitros com colorido variável; terço anterior do dorso varia do avermelhado ao preto; no meio aparece uma mancha preta, circundada por branco-amarelado em maior ou menor extensão; o terço apical é preto ou avermelhado-escuro. Pubescência elitral esparsa, amarelada, em toda a superfície, menos na mancha preta onde a pubescência é curta, negra e aveludada. Esternos torácicos preto-avermelhados; mancha de pubescência branca e densa nos metepimeros, metade apical dos metepisternos e lado posterior do metasterno. Abdômen com tegumento brilhante e mais escuro.

Dimensões, respectivamente macho/fêmea. Comprimento total, 7,1/5,0-8,5; comprimento do protórax, 2,2/1,8-1,9; maior largura do protórax, 1,5/1,0-1,6; comprimento do élitro, 4,1/3,0-5,6; largura umeral, 1,8/1,3-2,0.

Material tipo. Holótipo fêmea procedente da Colômbia, Boyaca: SFF Iguaque (Cabaña Mamarramos, 2855 m), 1330.VII.2000, P. Reina leg., armadilha de Malaise (IAHC). Parátipos: mesmos dados do holótipo, macho, fêmea, (MZSP; IAHC); mesma localidade, fêmea, 23.V-8.VI.2000, P. Reina leg., armadilha de Malaise (MCNZ); fêmea, mesma localidade, (La Planada, $\left.5^{\circ} 25^{\prime} \mathrm{N}, 73^{\circ} 27 \mathrm{~W}, 2850 \mathrm{~m}\right), 25 . \mathrm{VI}-13 . \mathrm{VII} .2000$, P. Reina leg., armadilha de Malaise (MZSP).

Discussão. Epropetes variabile sp. nov. pode ser comparada com E. howdenorum Galileo \& Martins, 2000 também descrita da Colômbia (Valle). Difere pela cabeça com pubescência, pelas antenas dos machos longas, ultrapassam o ápice elitral por mais de quatro artículos, pela ausência de manchas de pubescência branca nos lados do prosterno. Em E. howdenorum a cabeça é glabra, as antenas, nos machos, são um pouco mais longas que o corpo e os lados do prosterno têm mancha de pubescência branca.

\section{Heteropsini}

\section{Chrysoprasis aureicollis White, 1853}

Chrysoprasis aureicollis White, 1853: 149; Monné, 1994a: 24 (cat.); Napp \& Martins, 1998: 478.

Chrysoprasis brevicornis Bates, 1870: 415.

Espécie conhecida do Brasil (Amazonas e Pará) e da Venezuela (Amazonas), assinala-se agora para a Colômbia.

Material examinado. Colômbia, Amazonas: Parque Nacional Natural Amacayacu (Mocagua, $3^{\circ} 23^{\prime} \mathrm{S}, 70^{\circ} 06^{\prime} \mathrm{W}, 150 \mathrm{~m}$ ), fêmea, 14-21.VIII.2000, A. Parente leg., armadilha de Malaise (IAHC).

\section{Lamiinae Onciderini Ischiocentra punctata sp. nov.} Fig. 5

Etimologia. Latim, punctata $=$ pontuada .

Tegumento castanho-escuro. Cabeça revestida por pubescência alaranjada exceto nos pontos que são evidentes. Lobos oculares inferiores com o triplo do comprimento das genas. Antenas atingem o ápice dos élitros na extremidade do antenômero IX. Pronoto com pontos rasos e pubescência alaranjada; com uma elevação transversal que ocupa todo o pronoto menos em estreita região da base e do ápice. Cada élitro com uma faixa branco-alaranjada, oblíqua em sentido descendente da margem para a sutura que não chega a atingir; pequena mancha de pubescência concentrada, alaranjada, no dorso do quinto apical;

pontuação da metade basal densa e profunda; úmeros com tubérculo evidente. Esternos torácicos revestidos por pubescência alaranjada. Centro dos urosternitos I a IV com pubescência mais esparsa. Pernas revestidas por pubescência alaranjada.

Dimensões. Comprimento total, 14,1; comprimento do protórax, 2,5; maior largura do protórax, 3,7; comprimento do élitro, 10,5; largura umeral, 5,7.

Material-tipo. Holótipo fêmea, Colômbia, Cauca: Parque Nacional Natural Isla Gorgona (Antigua Laguna, $2^{\circ} 58^{\prime} \mathrm{N}$, $\left.78^{\circ} 11^{\prime} \mathrm{W}, 70 \mathrm{~m}\right), 24 . V I-9 . V .2000$, H. Torres leg., armadilha de Malaise (IAHC).

Discussão. Ischiocentra punctata sp. nov. distingue-se de I. monteverdensis Giesbert, 1984 pela faixa elitral brancoalaranjada; pela ausência de faixas longitudinais de pubescência branca na metade apical dos élitros; pelo pronoto sem rugas e pela ausência de faixa glabra junto a base do pronoto; pela metade anterior dos élitros forte e densamente pontuada. Em I. monteverdensis os élitros apresentam faixa irregular no meio e faixas longitudinais na metade apical de pubescência branca; o pronoto com grossas rugas transversais e uma faixa basal glabra; a metade anterior dos élitros com pontos menores.

\section{Cherentes niveilateris (Thomson, 1868)}

Eudesmus niveilateris Thomson, 1868: 78.

Eudesmus (?) niveilateris; Bates, 1885: 369.

Cherentes niveilateris; Gounelle, 1906: 273, fig. 1; Monné, 1994b: 41 (cat.).

Espécie com ampla distribuição já foi assinalada para o Panamá, Peru, Brasil (Goiás, Mato Grosso, Espírito Santo a São Paulo), o Paraguai e a Argentina. Expande-se a distribuição para a Colômbia.

Material examinado. Colômbia, Tolima: Mariquita (Cataratas de Medina), macho, 22-25.V.2001, V. Castro leg. (MNHB).

\section{Desmiphorini Blabia bicolor sp. nov. Fig. 6}

Etimologia. Latim, bicolor $=$ bicolor.

Cabeça com tegumento acastanhado recoberto por pubescência amarelada, mais densa no vértice. Lobos oculares superiores tão distantes entre si quanto a largura de um lobo;

Revista Brasileira de Zoologia 22 (1): 5-18, março 2005 
lobos oculares inferiores com o quádruplo do comprimento das genas. Antenas atingem a ponta dos élitros no meio do antenômero VIII; escapo, pedicelo e ápice do antenômero III, castanho-avermelhados. Protórax com tegumento vermelho-alaranjado no pronoto e castanho-avermelhado nas partes laterais e no prosterno; espinho lateral do protórax desenvolvido e ligeiramente voltado para trás. Pronoto com três gibosidades pouco elevadas: duas ântero-laterais e uma central; pontuação esparsa. Élitros alaranjados no dorso, margem lateral longitudinalmente acastanhada que emite, atrás do meio, um prolongamento oblíquo em direção à sutura; curta crista centro-basal; úmeros com tubérculo; espinhos apicais pretos, desenvolvidos e divergentes; na porção alaranjada os pontos são mais densos na metade basal e na parte acastanhada são contrastantes; examinados transversalmente à fonte luminosa os élitros mostram costas, a mais evidente ao lado da sutura. Pernas alaranjadas. Ápices dos meso- e dos metafêmures desarmados. Esternos torácicos acastanhados. Mesepisternos lisos. Lados do metasterno pontuados.

Dimensões. Comprimento total, 13,4; comprimento do protórax, 2,4; maior largura do protórax, 3,5; comprimento do élitro, 10,0; largura umeral, 4,0.

Material-tipo. Holótipo fêmea, Colômbia, Valle del Cauca: Quebrada El Pital (Río Calima), 20.IX.1980, R. Torres leg. (MNHB).

Discussão. O colorido de Blabia bicolor sp. nov. é característico e os élitros têm as margens escuras e o dorso alaranjado, caráter inédito para o gênero.

\section{Xenofreini Xenofrea triangularis sp. nov.}

Fig. 7

Etimologia. Latim, triangularis $=$ triangular. Alusivo a forma das manchas elitrais.

Cabeça com tegumento preto. Fronte revestida por pubescência esparsa, amarelada. Vértice com algumas escamas brancas entremeadas à pubescência. Lobos oculares superiores tão distantes entre si quanto a largura de um lobo. Antenas (macho) atingem o ápice dos élitros no meio do antenômero VI; pretas na base e mais avermelhadas para a extremidade; base dos antenômeros IV a VIII com anel estreito de pubescência branca. Protórax preto com pubescência castanha na maior parte da superfície; três a quatro manchas pequenas de pubescência alaranjada, principalmente, nos lados do pronoto. Todo pronoto com escamas brancas esparsas. Partes laterais do protórax com pubescência castanha entremeada por escamas brancas. Cada élitro com a região circum-escutelar de tegumento alaranjado; faixa de tegumento acastanhado do úmero ao meio; mancha de pubescência branca, triangular, que atinge a margem e a sutura; terço apical com áreas de pubescência alaranjada, irregulares e dispersas; pontuação densa até a mancha branca; terço apical com algumas escamas brancas entremeadas à pubescência. Mesepisterno, metepimeros, lados do metasterno e lados dos urosternitos com escamas brancas; mancha de pubescência alaranjada na metade apical dos metepisternos e lados do metasterno. Profêmures mais robustos que os médios e os posteriores; fêmures com escamas brancas esparsas.

Dimensões. Comprimento total, 7,5; comprimento do protórax, 1,4; maior largura do protórax, 2,5; comprimento do élitro, 5,3; largura umeral, 3,1.

Material-tipo. Holótipo macho, Colômbia, Amazonas: Parque Nacional Natural Amacayacu (Mocagua, $3^{\circ} 23^{\prime} \mathrm{S}, 70^{\circ} 06^{\prime} \mathrm{W}$, 150 m), 3-9.IV.2000, A. Parente leg., armadilha de Malaise (IAHC).

Discussão. Xenofrea triangularis sp. nov. assemelha-se a X. albofasciata Galileo \& Martins, 2001 descrita do Brasil meridional (Paraná e Santa Catarina) pela faixa larga de pubescência branca no meio dos élitros. X. triangularis difere pelos lobos oculares superiores tão distantes entre si quanto a largura de um lobo; pelo pronoto liso com manchas pequenas de pubescência alaranjada; pelo prosterno sem pubescência longa e densa (macho) e pela presença de áreas de pubescência amarelada na base dos élitros

Em X. albofasciata a distância entre os lobos oculares superiores é igual ao dobro da largura de um lobo; o pronoto é densamente pontuado, sem manchas de pubescência nos lados; o prosterno tem pubescência longa e densa (fêmea) e a base dos élitros é glabra.

\section{Acanthoderini \\ Oreodera curvata Martins \& Monné, 1993}

Oreodera curvata Martins \& Monné, 1993: 134, fig. 1; Monné, 1994c: 26 (cat.); Julio et al., 2000: 44 (holótipo).

Oreodera curvata foi descrita do Amazonas e assinalada para a Guiana Francesa. Registra-se agora para a Colômbia.

Material examinado. Colômbia, Amazonas: Parque Nacional Natural Amacayacu (Mocagua, $3^{\circ} 23^{\prime} \mathrm{S}, 7^{\circ} 06^{\prime} \mathrm{W}, 150 \mathrm{~m}$ ), macho, 3-9.IV.2000, A. Parente leg., armadilha de Malaise (IAHC).

\section{Oreodera melzeri Monné \& Fragoso, 1988}

Oreodera melzeri Monné \& Fragoso, 1988: 823, fig. 16; Monné, 1994c: 30 (cat.); Tavakilian et al., 1997: 315 (hosp.); Berkov \& Tavakilian, 1999: 188 (hosp.); Julio et al., 2000: 45 (tipo).

Originalmente descrita do Peru, Oreodera melzeri já foi dada como ocorrente na Guiana Francesa e no Brasil (Amazonas). Amplia-se a distribuição para a Colômbia.

Material examinado. ColômbIa, Putumayo: Parque Nacional Natural La Paya, (Cabaña Viviano Cocha, $0^{\circ} 7^{\prime} \mathrm{S} 74^{\circ} 56^{\prime} \mathrm{W}$, 320m), macho, 20-26.IX.2001, D. Campos leg., armadilha de Malaise (IAHC).

\section{Oreodera nivea sp. nov. Fig. 8}

Etimologia. Latim, niveus $=$ de neve. Alusivo ao colorido das manchas elitrais.

Tegumento castanho-avermelhado. Cabeça revestida por pubescência castanho-amarelada. Antenas castanhas com a base 

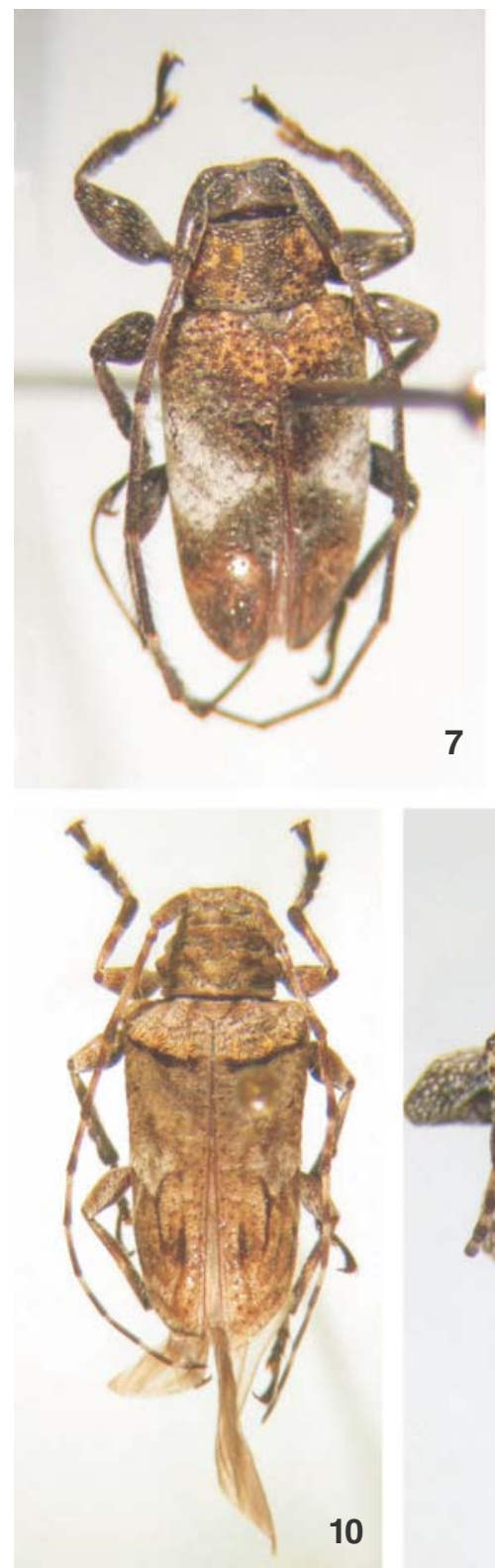

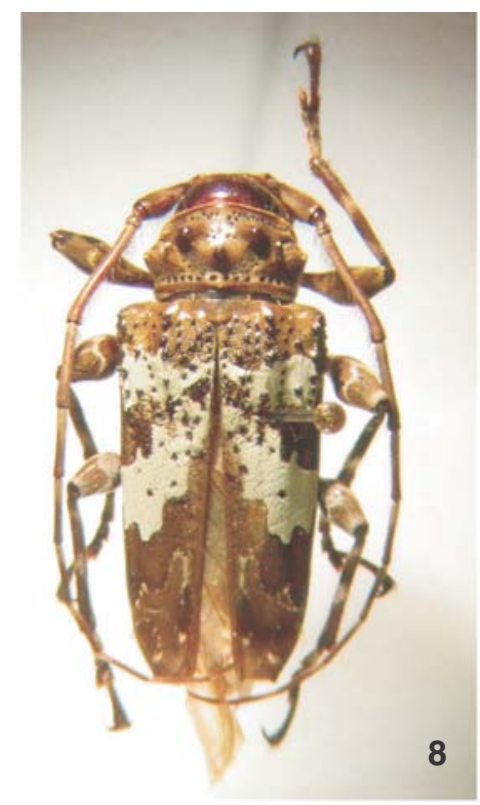

8
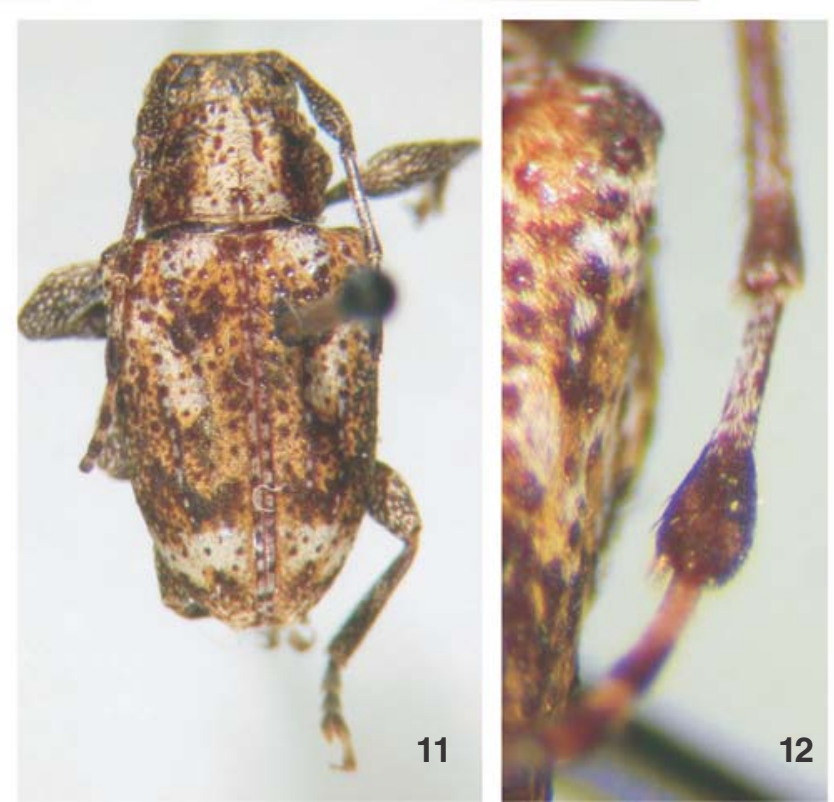

Figuras 7-13. Habitus. (7) Xenofrea triangularis sp. nov., holótipo fêmea,7,5 mm; (8) Oreodera nivea sp. nov., parátipo fêmea,19,7 mm; (9) Oreodera adornata sp. nov., holótipo macho, 13,5 mm; (10) Oreodera advena sp. nov., holótipo fêmea, 11,2 mm; (11) Irundisaua ocularis sp. nov., holótipo macho, 9,2 mm; (13) Carterica rubra sp. nov., holótipo macho, 9,4 mm. Antenômero IV (12) Irundisaua ocularis sp. nov.

dos antenômeros aneladas de esbraquiçado. Protórax revestido por pubescência castanho-amarelada; tubérculo lateral cônico com pequena mancha de pubescência branca na ponta; circundado por sulco profundo. Pronoto com três tubérculos, glabros no topo: dois látero-anteriores e um centro-basal; para o lado externo dos tubérculos látero-anteriores pequena mancha de pubescência branca; atrás do tubérculo central e dos ânterolaterais pontos finos; pontos da fileira transversal basal maiores que os da fileira apical. Élitros com pubescência predominantemente castanho-amarelada; cada um com uma grande mancha de pubescência branca de contornos irregulares que envolve uma mancha lateral do colorido do fundo; duas manchas pequenas 
de pubescência branca de cada lado do escutelo; terço apical com desenho fino e irregular de pubescência branca; quarto anterior dos élitros com grânulos, os maiores localizados sobre a crista centro-basal; extremidades elitrais transversalmente truncadas com espículo externo. Fêmures com pubescência castanho-amarelada e anel central irregular de pubescência branca. Tíbias com anéis basal e central de pubescência branca. Tarsômeros I e II com pubescência esbranquiçada. Face ventral do corpo com pubescência castanho-amarelada.

Dimensões, fêmea. Comprimento total, 15,0-19,7; comprimento do protórax, 3,4; maior largura do protórax, 6,5-6,7; comprimento do élitro, 13,8-14,0; largura umeral, 8,1-8,4.

Material-tipo. Holótipo fêmea, ColômBia, Valle del Cauca: Quebrada el Pital (Río Calima), 10.VII.1981, D. Torres leg. (MNHN). Parátipo fêmea, Colômbia, Chocó: Parque Nacional Natural Enseada de Utría (Cocalito, $6^{\circ} 1^{\prime} \mathrm{N}, 77^{\circ} 20^{\prime} \mathrm{W}, 20 \mathrm{~m}$ ), 26.XII.2000-1.II.2001, J. Pérez leg. (IAHC).

Discussão. Oreodera nivea sp. nov. assemelha-se a $O$. semialba Bates, 1874 descrita da Nicarágua e que não conhecemos. O. nivea difere pela presença das pequenas manchas de pubescência branca de cada lado do escutelo; pela grande mancha de pubescência branca dos élitros mais distante da base e com limite posterior bem ascendente para a sutura; pela pontuação elitral da metade posterior da mancha branca praticamente ausente. Em O. semialba, os lados do escutelo não tem manchas de pubescência branca; a grande mancha de pubescência branca dos élitros é muito próxima da base, principalmente nos lados, e o limite posterior é oblíquo em sentido descendente da margem para a sutura e a parte posterior da mancha branca é evidentemente pontuada.

\section{Oreodera adornata sp. nov.}

\section{Fig. 9}

Etimologia. Latim, adornata $=$ embelezada.

Tegumento castanho-escuro. Cabeça revestida por pubescência castanho-amarelada. Antenas acastanhadas com a base dos antenômeros III-VII anelada de branco. Protórax revestido por pubescência castanho-amarelada; tubérculo lateral não circundado por sulco. Pronoto com três tubérculos: dois látero-anteriores e um centro-basal; alguns pontos atrás dos tubérculos látero-anteriores do pronoto e do tubérculo lateral do protórax; fileira transversal de pontos da base constituída por pontos esparsos e fileira anterior com dois ou três pontos. Élitros revestidos por pubescência castanho-amarelada; cada um com manchas de pubescência branca: uma de contorno irregular, no quinto anterior, afastada da sutura; uma atrás do meio, também de contorno irregular, oblíqua em sentido descendente da margem para a sutura; uma faixa branca estreita no quarto apical que se inicia na sutura, dirige-se para atrás onde se trifurca num ramo para o lado da margem, um ramo para o ápice em direção à margem elitral externa e um ramo em direção à sutura prolongado até o ápice. Metade anterior dos élitros com grânulos moderadamente densos. Extre- midades elitrais obliquamente truncadas. Face ventral revestida por pubescência castanha-amarelada.

Dimensões. Comprimento total, 13,5; comprimento do protórax, 2,4; maior largura do protórax, 4,5; comprimento do élitro, 9,9; largura umeral, 5,7.

Material-tipo. Holótipo macho, ColôMBIA, Caquetá: San José de Fragua, $\left(1^{\circ} 20^{\prime} \mathrm{N}, 76^{\circ} 6^{\prime} \mathrm{W}, 1700 \mathrm{~m}\right)$, 9-13.IX.2000, E. González leg., armadilha de Malaise (IAHC).

Discussão. O padrão de colorido de O. adornata sp. nov. é característico e não pode ser confundido com o de nenhuma outra espécie do gênero.

\section{Oreodera advena sp. nov. Fig. 10}

Etimologia. Latim, advena $=$ estranha.

Tegumento avermelhado. Cabeça revestida por pubescência amarelo-esbranquiçada com alguns pontos atrás dos lobos oculares superiores. Escapo revestido por pubescência amarelo-esbranquiçada com pontos pequenos. Antenômero III com pubescência amarelo-esbranquiçada exceto anel pouco evidente no quarto basal e o ápice enegrecidos; antenômeros IV-XI com ápices pretos de largura gradualmente maior em direção aos apicais. Protórax revestido por pubescência amarelada; tubérculo lateral não circundado por sulco; as três gibosidades do pronoto revestidas por pubescência; pronoto com pontos pequenos, rasos e sem fileiras de pontos maiores junto a base. Lados do metasterno com pubescência branca, mais longa. Élitros com pubescência predominantemente amarelada no quinto basal que está delimitada posteriormente por faixa de pubescência preta iniciada no ombro e estendida obliquamente em direção à sutura; à frente dessa faixa, pêlos mais longos, amarelos. Da faixa preta até o meio dos élitros, a superfície é irregular, com mancha de pubescência mais clara dorsal; no terço apical de cada élitro, três faixas estreitas, longitudinais, de pubescência preta; no quinto apical mancha transversal de pubescência branca, pouco contrastante; extremidade elitral ocupada por pubescência branca. Élitros sem grânulos com pontos recobertos pela pubescência, principalmente, na metade anterior; na metade apical, uma linha de pontos acompanha a sutura. Fêmures revestidos por pubescência branca com pontos pequenos e contrastantes. Tíbias com ápice enegrecido. Tarsômeros I e V esbranquiçados na base; os demais revestidos por pubescência preta. Urosternitos com pubescência branca e pontos contrastantes.

Dimensões. Comprimento total, 11,2; comprimento do protórax, 1,8; maior largura do protórax, 3,2; comprimento do élitro, 8,5; largura umeral, 4,8.

Material-tipo. Holótipo fêmea, Colômbia, Boyaca: SFF Iguaque (Quebrada Los Francos, $5^{\circ} 25^{\prime} \mathrm{N}, 73^{\circ} 27^{\prime} \mathrm{W}, 2860 \mathrm{~m}$ ), 724.II.2001, P. Reina leg., armadilha de Malaise (IAHC).

Discussão. Oreodera advena sp. nov. caracteriza-se pela faixa preta do quinto basal dos élitros, precedida por pêlos amarelados mais longos que a pubescência geral. Além disso, a metade anterior dos élitros não têm grânulos. 


\section{Necalphus decoratus (Monné \& Magno, 1992) comb. nov.}

Myoxomorpha decorata Monné \& Magno, 1992: 717.

Necalphus maranduba Galileo \& Martins, 2003: 263. Syn. nov.

Alertados por Miguel A. Monné (Museu Nacional, Rio de Janeiro) verificou-se que Necalphus maranduba é sinônima de Myoxomorpha decorata Monné \& Magno, 1992 e que a transferência de $M$. decorata para Necalphus faz-se necessária.

\section{Irundisaua gen. nov.}

Etimologia.Tupi, irundisaua $=$ quarto. Alusivo ao antenômero IV altamente modificado.

Espécie-tipo, Irundisaua ocularis sp. nov.

Fronte tão larga quanto longa. Olhos divididos, finamente granulados; distância entre os lobos oculares superiores maior que o quádruplo da largura de um lobo; lobos oculares inferiores mais curtos que as genas. Escapo atinge o terço anterior do protórax. Antenômero III subigual em comprimento ao escapo, pouco mais longo que o IV e sem alargamento no ápice; antenômero IV (fig. 12) com aproximadamente o dobro do V e com a metade apical gradualmente alargada e achatada; antenômero VI e VII em conjunto pouco mais curtos que o V; (antenas quebradas no ápice do antenômero VII). Partes laterais do protórax com gibosidade no nível do meio e um tubérculo entre a gibosidade e a margem anterior. Pronoto com duas gibosidades látero-anteriores. Processo prosternal curvo, com largura subigual a de uma procoxa. Processo mesosternal truncado anteriormente, mais largo que uma mesocoxa. Élitros com crista centro-basal curta, encimada por grânulos restritos à declividade basal; restante da superfície sem elevações; extremidades obliquamente truncadas e desarmadas. Protíbias alargadas e achatadas desde a base. Meso- e metatíbias gradualmente alargadas para o ápice. Último urosternito mais longo que os três precedentes

Discussão. Irundisaua gen. nov. apresenta o antenômero IV achatado e acentuadamente alargado na metade apical. Em Acakyra Martins \& Galileo, 1996 o antenômero III (MarTins \& GaLileo 2001: 104, figs 3 e 4) é achatado e alargado na metade apical, os antenômeros IV-XI são muito curtos e o protórax tem espinho lateral. Esses caracteres são bem diferentes daqueles de Irundisaua onde o antenômero IV é apenas mais curto do que o III e o protórax tem tubérculo arredondado no topo.

Irundisaua também lembra, pelo aspecto geral, Eupromerella cujas antenas são normais e a maioria das espécies tem o protórax com espinho lateral.

\section{Irundisaua ocularis sp. nov.}

Figs 11,12

Etimologia. Latim, ocularis $=$ dos olhos. Alusivo aos olhos divididos.

Tegumento preto. Fronte com alguma pubescência amarelada nos lados e grumos esparsos de pubescência branca no meio. Áreas malares, partes laterais do protórax, partes ven- trais do corpo e fêmures com pincéis pequenos de pubescência branca. Vértice com pubescência amarelada e bem interrompida por numerosas áreas glabras. Escapo, pedicelo e antenômero III com pequenos pincéis de pubescência branca. Antenômeros IV-VII com a metade basal branca e apical preta. Pronoto com larga área central de pubescência branca, gradualmente mais estreita e que vai da base ao ápice; gibosidades ântero-laterais com pubescência preta; pubescência variegada de amarelado para as partes laterais do protórax. Élitros com pubescência de três cores: amarelo, branco e preto. Branco: mancha entre a crista e a sutura; faixa irregular, oblíqua em sentido descendente, do úmero até o meio e não chega a tocar a sutura; faixa transversal, anteapical com bordas irregulares. Amarelo: restante da superfície elitral interrompida por áreas e pontos de pubescência preta.

Dimensões. Comprimento total, 9,2; comprimento do protórax, 2,0; maior largura do protórax, 3,3; comprimento do élitro, 6,3; largura umeral, 4,5. Largura da fronte entre os lobos oculares, 1,5. Largura do lobo ocular superior, 0,2; distância entre os lobos oculares superiores, 0,9. Comprimento do lobo ocular inferior, 0,5 ; comprimento da área malar, 0,8 . Escapo, 1,7; pedicelo, 0,5; antenômero III, 1,8; antenômero IV, 1,6; antenômero V, 0,7.

Material-tipo. Holótipo macho, Colômbia, Boyaca: Santa Maria (Afueras del pueblo), 3.V.1999, J. Gordillo leg. (MHNB).

\section{Colobotheini \\ Carterica cincticornis Bates, 1865}

Carterica cincticornis Bates, 1865: 214; Monné, 1995: 23 (cat.).

Descrita originalmente do Brasil, Amazonas: Tefé.

Material examinado. Colômbia, Amazonas: Parque Nacional Natural Amacayacu (San Martín, 3²3’S, 7006’W, 150 m), macho, 1-8.IX.2000, B. Amado leg., armadilha de Malaise (IAHC).

\section{Carterica rubra sp. nov. \\ Fig. 13}

Etimologia. Latim, rubra = vermelha.

Tegumento preto; quatro quintos do antenômero IV branco; lados do pronoto e, largamente, nos lados dos élitros, vermelho-alaranjados. Cabeça com pubescência esbranquiçada visível conforme a incidência da luz. Fronte alongada, larga. Lobos oculares superiores mais distantes entre si do que os tubérculos anteníferos entre si. Lobos oculares inferiores mais curtos que as genas. Escapo atinge a base dos élitros, apenas engrossado para o ápice. Lados do protórax convergentes para a parte anterior com espinho de ápice voltado para trás, no nível do quarto basal e depressão acentuada à frente do meio. Pronoto com duas faixas laterais largas de pubescência vermelho-alaranjada. A faixa de pubescência vermelho-alaranjada dos élitros estende-se dos úmeros ao quarto apical; cada élitro com duas costas: uma dorsal e outra, mais acentuada, no meio, que se inicia no úmero e vai até o ápice; extremidades com espi- 
nho externo e bissinuosas para o lado da sutura. Face ventral com pubescência esbranquiçada curta e esparsa. Fêmures longamente pedunculados e pouco clavados.

Dimensões. Comprimento total, 9,4; comprimento do protórax, 1,3; maior largura do protórax, 1,8; comprimento elitral, 7,0; largura umeral, 2,0.

Material-tipo. Holótipo macho, ColômbIa, Nariño: RN La Planada (Vía Hondón, $1^{\circ} 15^{\prime} \mathrm{N}, 78^{\circ} 15^{\prime}$ W, 1930 m), 2-16.VII.2000, G. Oliva leg., armadilha de Malaise (IAHC).

Discussão. O colorido corporal de C. rubra é único e não pode ser confundido com o das demais espécies do gênero.

\section{Hemilophini}

\section{Cotyadesmus nom. nov.}

Paradesmus Galileo \& Martins, 2003: 267. rico.

Etimologia.Tupi, coty = ao lado de; adesmus, nome gené-

O nome Paradesmus Saussure, 1869 já foi utilizado para Myriapoda segundo o Sr. John K. Page do Zoological Record que chamou atenção para essa homonímia. Propõe-se Cotyadesmus para substituí-lo.

\section{Cotyadesmus iuba (Galileo \& Martins, 2003) comb. nov.}

Paradesmus iuba Galileo \& Martins, 2003: 267, fig. 6.

\section{AGRADECIMENTOS}

Ao Sr. John K. Page e ao Dr. Miguel A. Monné pelas informações sobre Paradesmus e Myoxomorpha; ao Dr. Fernando Fernández e à Bióloga Claudia Martínez pelo empréstimo do material que foi colecionado com o apoio NSF-DEC-0205982; a Rafael Santos de Araújo (MCNZ) pela execução das fotografias.

\section{REFERÊNCIAS BIBLIOGRÁFICAS}

Aurivillius, C. 1910. Neue oder wenig bekannte Coleoptera Longicornia. 11. Arkiv för Zoologi, Uppsala, 7 (3): 143-187.

Aurivillius, C. 1912. Coleopterorum Catalogus, pars 39, Cerambycidae: Cerambycinae. Berlin, W. Junk, 574p.

Aurivillius, C. 1926. Cerambyciden gesammelt von Dr. A. Roman in Brasilien in den Jahren 1923-1924. Arkiv för Zoologi, Uppsala, 18B (14): 1-6.

BAtes, H.W. 1865. Contributions to an insect fauna of the Amazon Valley. Coleoptera: Longicornes. Annals and Magazin of Natural History, London, 15 (3): 213-225, 382-394; 16: 101-113, 167-182, 308-314.

Bates, H.W.1870. Contributions to an insect fauna of the Amazon Valley (Coleoptera: Cerambycidae). Transactions of the Entomological Society of London, London, 1870: 243335, 391-444.

Bates, H.W. 1872. On the longicorn Coleoptera of Chontales, Nicaragua. Transactions of the Entomological Society of London, London, 1872: 163-238.
BAtes, H.W. 1885. Biologia Centrali-Americana, Insecta, Coleoptera, suppl. to Longicornia. London, British Museum (Natural History), vol. 5, p. 249-436.

Berkov, A. \& G.L. TavakiLian. 1999. Hosts utilization of the Brazil nut family (Lecythidaceae) by sympatric wood-boring species of Palame (Coleoptera, Cerambycidae, Lamiinae, Acanthocinini). Biological Journal of the Linnean Society, London, 67: 181-198.

Bodkin, G.E. 1919. Notes on the Coleoptera of British Guiana. Entomologist's Montly Magazin, London, 55: 264-272.

BUQUET, J.B.L. 1859. Mémoire sur deux genres nouveaux de coléoptères de la famille des longicornes (Oxilus et Sthelenus), suivi de la description de plusieurs espèces appartenant aux genres Platyarthron, Oeme (Sclerocerus Dej.), Clytus, Apriona, Cerosterna et Acanthoderus. Annales de la Societé Entomologique de France, Paris, 7 (3): 619-636.

Dejean, P.F.M.A. 1821. Catalogue de la collection de Coléoptères de M. le baron Dejean. Paris, Crevot. VIII+136+IIp.

Erichson, W.F. 1847. Conspectus insectorum coleopterorum quae in Republica Peruana observata sunt. Archiv für Naturgeschichte, Berlin, 13: 67-185.

FABRICIUS, J.C. 1801. Systema eleutheratorum secundum ordines, genera, species: adiectis synonymis, locis, observationibus, descriptionibus. Kiliae, Bibliopoli Academici Novi, vol. 2, 687p.

Fuchs, E. 1961. Neue Cerambyciden aus Südbrasilien. Pesquisas, (Zool.), Porto Alegre, 12: 1-10.

GaHAN, C.J. 1892. Notes on longicorn Coleoptera of the group Cerambycinae, with descriptions of new genera and species. Annals and Magazin of Natural History, London, 9 (6): 19-32.

Galileo, M.H.M. \& U.R. Martins. 2003a. Cerambycidae (Coleoptera) da Colômbia. III. Cerambycinae com olhos finamente granulados. Iheringia, Série Zoologia, Porto Alegre, 93 (1): 31-36.

Galileo, M.H.M. \& U.R. Martins. 2003b. Cerambycidae (Coleoptera) da Colômbia. V. Lamiinae com unhas tarsais divergentes. Iheringia, Série Zoologia, Porto Alegre, 93 (2): 167-172.

Galileo, M.H.M. \& U.R. Martins. 2003c. Cerambycidae (Coleoptera) da Colômbia. VI. Lamiinae com unhas tarsais divaricadas ou bífidas. Iheringia, Série Zoologia, Porto Alegre, 93 (3): 255-270.

Gemminger, M. \& E. von Harold. 1872. Catalogus Coleopterorum hucusque descriptorum synonymicus et systematicus. Monachii, vol. 9, p. 2669-2988.

GounelLe, E. 1906. Note sur deux lamiaires américains placés avec doute dans le genre Eudesmus et descriptions de deux genres nouveaux. Bulletin de la Societé Entomologique de France, Paris, 1906: 272-275.

Gounelle, E. 1909. Liste des cérambycides de la région de Jatahy, État de Goyaz, Brésil. Annales de la Societé Entomologique de France, Paris, 77: 587-688. 
Gyllenhal, L. 1817. In: C.J. Schoenherr. Appendix ad Synonymia Insectorum. Scaris, Officina Lewerentziana. vol. 1 (3), 266p.

Huedepohl, K.E. 1988. Sobre o gênero Eusapia Gounelle, 1909 (Coleoptera, Cerambycidae, Cerambycinae, Hesperophanini). Revista Brasileira de Entomologia, São Paulo, 32 (3-4): 525-528.

Julio, C.E.A.; J.A. Giorgi \& M.A. Monné. 2000. Os tipos primários de Cerambycidae (Coleoptera) da coleção do Museu Nacional - Rio de Janeiro. Publicações Avulsas do Museu Nacional, Rio de Janeiro, 84: 1-54.

KIRSCH, T.F. 1875. Beitrage zur Kenntnis der Peruanischen Käferfauna auf Dr. Abendroth's basirt (Funftes Stuck). Deutche Entomologische Zeittung, Berlin, 19 (2): 241-304.

LACORDAIRE, J.T. 1830. Mémoire sur les habitudes des insectes coléoptères de l'Amérique méridionale. Annales des Sciences Naturelles, Paris, 20: 185-191; 21: 149-194.

LaCordaire, J.T. 1869. Histoire Naturelle des Insectes. Genera des Coléoptères, ou exposé méthodique et critique de tous les genres proposés jusqu'ici dans cet ordre d'insectes. Paris, Roret, vol. 8, 552p.; vol. 9 (1), 409p.

LANE, F. 1956. Cerambycoidea Neotropica nova IV (Coleoptera). Dusenia, Curitiba, 7 (1):1-32.

Maes, J.-M.; A. Allen; M.A. Monné \& F.T. Hovore. 1994. Catálogo de los Cerambycidae (Coleoptera) de Nicaragua. Revista Nicaraguense de Entomologia, León, 27: 1-58.

Martins, U.R. 1962. Ibidionini (Coleoptera, Cerambycinae) XV. Novas espécies, notas sinonímicas, redescrições. Papéis Avulsos do Departamento de Zoologia, São Paulo, 14 (30): 267-310.

Martins, U.R. 1967. Monografia da tribo Ibidionini (Coleoptera, Cerambycinae). Parte I. Arquivos de Zoologia, São Paulo, 16 (1): 1-320.

Martins, U.R. 1968. Monografia da tribo Ibidionini (Coleoptera, Cerambycinae). Parte II. Arquivos de Zoologia, São Paulo, 16 (2): 321-630.

Martins, U.R. 1976. Sistemática e evolução da tribo Piezocerini (Coleoptera, Cerambycidae). Arquivos de Zoologia, São Paulo, 27 (3-4): 165-370.

MarTins, U.R. 1981. Revisão do gênero Atenizus; os gêneros Tessaropa e Methia na América do Sul e descrição de novos taxa em Methiini (Coleoptera, Cerambycidae). Revista Brasileira de Entomologia, São Paulo, 25 (1): 9-17.

Martins, U.R. 1995. Notas e descrições em Elaphidionini (Coleoptera, Cerambycidae). Revista Brasileira de Entomologia, São Paulo, 39 (4): 741-749.

Martins, U.R. 1997. Tribo Oemini, p. 3-155. In: U.R. Martins (Org.). Cerambycidae sul-americanos (Coleoptera). São Paulo, Sociedade Brasileira de Entomologia, vol. 1, 217p.

Martins, U.R. 1999. Tribo Eburiini, p. 119-391. In: U.R. Martins (Org.). Cerambycidae sul-americanos (Coleoptera). São Paulo, Sociedade Brasileira de Entomologia, vol. 3, 418p.

Martins, U.R. 2003. Cerambycidae sul-americanos
(Coleoptera). São Paulo, Sociedade Brasileira de Entomologia, vol. 6, 232p.

Martins, U.R. \& M.H.M. Galileo. 1999. Tribo Hesperophanini, p. 1-117. In: U.R. MarTins (Org.). Cerambycidae sul-americanos (Coleoptera). São Paulo, Sociedade Brasileira de Entomologia, vol. 3, 418p.

Martins, U.R. \& M.H.M. Galileo. 2001. Duas espécies novas do gênero Acakyra Martins \& Galileo, 1996 (Coleoptera, Cerambycidae, Lamiinae, Acanthoderini). Revista Brasileira de Entomologia, Curitiba, 45 (2): 103-105.

Martins, U.R. \& M.H.M. Galileo. 2002a. Cerambycidae (Coleoptera) da Colômbia. I. Eburiini (Cerambycinae). Iheringia, Série Zoologia, Porto Alegre, 92 (4): 5-10.

Martins, U.R. \& M.H.M. Galileo. 2002b. Cerambycidae (Coleoptera) da Colômbia. II. Ibidionini (Cerambycinae). Iheringia, Série Zoologia, Porto Alegre, 92 (4): 11-18.

Martins, U.R. \& M.H.M. Galileo. 2003. Cerambycidae (Coleoptera) da Colômbia. IV. Cerambycinae com olhos grosseiramente granulados. Revista Brasileira de Entomologia, São Paulo, 47 (2):175-180.

Martins, U.R. \& M.A. Monné. 1993. Novas espécies de Oreodera A.-Serville, 1835 e Alphus White, 1855 (Coleoptera, Cerambycidae, Lamiinae, Acanthoderini) da América do Sul. Iheringia, Série Zoologia, Porto Alegre, (74): 133-140.

Martins, U.R. \& M.A. Monné. prelo. Tribo Cerambycini, Sphalotrichina, p. 1-218. In: U.R. MarTins (Org.). Cerambycidae sul-americanos (Coleoptera). São Paulo, Sociedade Brasileira de Entomologia, vol. 5, 284p.

Monné, M.A. 1993a. Catalogue of the Cerambycidae (Coleoptera) of the western hemisphere. Part I. São Paulo, Sociedade Brasileira de Entomologia, 76p.

Monné, M.A. 1993b. Idem. Part II. Ibidem, 77p.

Monné, M.A. 1993c. Idem. Part III. Ibidem, 52p.

Monné, M.A. 1993d. Idem. Part IV. Ibidem, 129p.

Monné, M.A. 1993e. Idem. Part V. Ibidem, 100p.

Monné, M.A. 1993f. Idem. Part VI. Ibidem, 47p.

Monné, M.A. 1993g. Idem. Part VII. Ibidem, 81p.

Monné, M.A. 1993h. Idem. Part VIII. Ibidem, 97p.

Monné, M.A. 1993i. Idem. Part IX. Ibidem, 131p.

Monné, M.A. 1994a. Idem. Part X. Ibidem, 81p.

Monné, M.A. 1994b. Idem. Part XV. Ibidem, 108p.

Monné, M.A. 1994c. Idem. Part XVII. Ibidem, 110p.

Monné, M.A. 1995. Idem. Part XIX. Ibidem, 94p.

Monné, M.A. 2001. Catalogue of the Neotropical Cerambycidae (Coleoptera) with known host plant - Part I: Subfamily Cerambycinae, Tribes Achrysonini to Elaphidiini. Publicações Avulsas do Museu Nacional, Rio de Janeiro, 88: 1108.

Monné, M.A. \& P.R. Magno 1992. Novas espécies de Acanthoderini neotropicais II. (Coleoptera, Cerambycidae, Lamiinae). Revista Brasileira de Entomologia, São Paulo, 36 (4): 717-721.

Monné, M.A. \& S.A. Fragoso. 1988. Novas espécies e sinonímia 
de Oreodera Audinet-Serville, 1835 (Coleoptera, Cerambycidae, Lamiinae, Acanthoderini). Revista Brasileira de Biologia, Rio de Janeiro, 48 (4): 811-831.

NAPr, D.S. 1994. Revisão do gênero Orthostoma Lepeletier \& A.Serville, 1830 e descrição de Aglaoschema, gen. n. (Coleoptera, Cerambycidae, Compsocerini). Revista Brasileira de Entomologia, São Paulo, 38 (3-4): 645-660.

NAPP, D.S. \& U.R. MARTINs. 1984a. Notas e descrições em Callidiopini (Coleoptera, Cerambycidae). Revista Brasileira de Entomologia, São Paulo, 28 (1): 51-58.

NAPP, D.S. \& U.R. Martins. 1984b. Gêneros Periboeum Thomson, 1864 e Rhomboidederes Zajciw, 1963 (Coleoptera, Cerambycidae): chave para as espécies, sinonímias e descrições. Papéis Avulsos de Zoologia, São Paulo, 35 (11): 125 133.

NAPP, D.S. \& U.R. Martins. 1998. Revisão do gênero Chrysoprasis A.-Serville, 1834 (Coleoptera, Cerambycidae). IV. Grupo hypocrita. Revista Brasileira de Entomologia, São Paulo, 41 (2-4): 465-499.

Newman, E. 1840. Descriptions of a few longicorns, MS names of which are published in the sale-catalogue of Mr. Children's Insects. Magazin of Natural History, London, (n.s.) 4: 194-196.

Olivier, A.G. 1795.Entomologie ou histoire naturelle des insectes. Coléoptères. Paris, Desray, vol. 4, 519p.

Tavakilian, G.L. 1996. In: V. Hequet. Longicornes de Guyane. Cayenne, Silvolab, III+36p.

Tavakilian, G.L.; A. Berkov; B. Meurer-Grimes \& S. Mori. 1997.

Recebido em 15.VI.2004; aceito em 24.XI.2004.
Neotropical tree species and their faunas of xylophagous longicorns (Coleoptera: Cerambycidae) in French Guiana. The Botanical Review, New York, 63 (4): 304-355.

Tномsоn, J. 1860. Essai d'une classification de la famille des cérambycides et matériaux pour servir a une monographie de cette famille. Paris, Bouchard-Huzard, 404p.

Thomson, J. 1864. Systema cerambycidarum ou exposé de tous les genres compris dans la famille des cérambycides et familles limitrophes. Mémoires de la Societé Royale des Sciences Naturelles, Liège, 19: 1-540.

Thomson, J. 1865. Diagnoses d'espèces nouvelles qui seront décrites dans l'appendix du systema cerambycidarum. Mémoires de la Societé Royale des Sciences Naturelles, Liège, 19: 541-578.

Thomson, J. 1867. Ibidionitarum species novae. Physis Recueil d'Histoire Naturelle, Paris, 1 (3): 133-163.

Thomson, J. 1868. Révision du groupe des oncidérites (Lamites, cérambycides, coléoptères). Physis Recueil d'Histoire Naturelle, Paris, 2 (5): 41-92.

Thomson, J. 1878. Typi cerambycidarum Musei Thomsoniani. (2e. mémoire). Revue et Magazin de Zoologie, Paris, 6 (3): $1-33$.

White, A. 1853. Catalogue of the coleopterous insects in the collection of the British Museum. Longicornia 1. London, British Museum (Natural History). vol. 7, 174p.

White, A. 1855. Catalogue of the coleopterous insects in the collection of the British Museum. Longicornia 2. London, British Museum (Natural History), vol. 8, p. 175-412. 